\title{
Clinical Reasoning: A 65-Year-Old Woman With Tremor
}

Jing Ye, MD, * Hua Cao, MD, * Lizhang Chen, MD, Song Lei, MD, Mei Liu, MD, Xiuying Long, MD, Guangzong Li, MD, and Hongbo Zheng, MD

Neurology ${ }^{\circledR}$ 2021;97:e1257-e1261. doi:10.1212/WNL.0000000000012262

\author{
Correspondence \\ Dr. Li \\ liguangzong1979@163.com \\ or Dr. Zheng \\ Hongbo_zheng@126.com
}

\section{Section 1}

A 65-year-old woman was referred to our hospital for the evaluation of tremor, which had initially appeared in her right upper limb 3 years previously and progressed to her left upper limb and head 2 years previously. The tremor was most prominent during movement, but also occurred during rest. The patient felt unsteady when walking, although she denied falling and slowness of movement and symptoms of dysautonomia (e.g., positional lightheadedness, urinary dysfunction). She reported that her short-term memory had worsened and that the tremor intruded on her activities of daily living. The patient reported no medical history or previous trauma, hypoxic insult, or neurotoxic exposure, and no drug or alcohol use. There was no family history of tremor.

Neurologic examination revealed distal asymmetric medium-amplitude tremors in both upper limbs (more pronounced on the right) at rest and with movement (postural and kinetic). The head tremor manifested as the "yes-yes" type. The tremors were more prominent with movement and had an intention component and low frequency. They were exacerbated with cognitive activity. The patient had no proximal wing-beating tremor or dystonic posturing in the hands or neck. Bradykinesia and rigidity were absent. Her gait was slightly unsteady, but not ataxic. Fingerto-nose testing revealed subtle dysmetria in the right arm. All other findings of neurologic examination, including the assessment of rapid alternating movements, muscle tone, and reflexes, were normal. The patient's Mini-Mental State Examination score was 28 and her Montreal Cognitive Assessment score was 20, which were expected given that she had 6 years of schooling.

\section{Questions for Consideration:}

1. What is the tremor phenomenology?

2. What is the differential diagnosis?

3. What is your initial approach to investigation?

GO TO SECTION 2

\footnotetext{
*These authors contributed equally to this work.
}

From the Department of Neurology (J.Y., M.L., X.L., G.L.), the Sixth People's Hospital of Chengdu; and the West China School of Nursing/Departments of Neurosurgery (H.C.), Neurology (L.C., H.Z.), and Pathology (S.L.), West China Hospital, Sichuan University, Chengdu, China.

Go to Neurology.org/N for full disclosures. Funding information and disclosures deemed relevant by the authors, if any, are provided at the end of the article. 

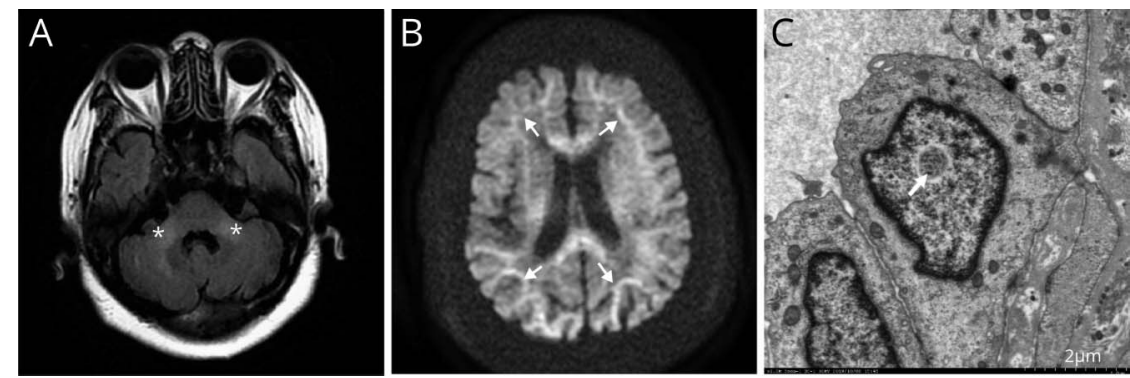

Brain MRI showed hyperintensity in the bilateral middle cerebellar peduncles on fluid-attenuated inversion recovery sequences (A, asterisks) and hyperintensity in the corticomedullary junction and corpus callosum on diffusion-weighted sequences (B, arrows). (C) Skin biopsy revealed intranuclear inclusions in the sweat gland cells (arrow).

\section{Section 2}

Tremor phenomenology aids the establishment of a diagnosis. Key aspects of tremor include its location and anatomic distribution, axis, frequency, amplitude, positionality, and setting (i.e., occurring at rest or with movement, with posture). In the present case, the patient presented with chronic progressive tremors occurring at rest and with movement, but more prominent with movement and having an intention component. She also had cognitive and balance complaints. The differential diagnosis is limited, including essential tremor plus, other tremor types (e.g., dystonic and Holmes), tremor secondary to medication use or underlying medical condition (i.e., Wilson disease), tremor caused by a structural lesion (i.e., tumor, multiple sclerosis lesion, cerebral infarction in the midbrain or thalamus), and psychogenic tremor.

The initial workup included blood cell counts; assessment of liver, kidney, and thyroid function; measurement of electrolytes, glucose, ammonia, and serum ceruloplasmin; CSF analysis; EMG; and cranial MRI. All findings were normal, except that the T2-weighted fluid-attenuated inversion recovery (FLAIR) MRI sequence showed hyperintensity in the bilateral middle cerebellar peduncles (MCPs) and periventricular white matter (Figure, A).

\section{Questions for Consideration:}

1. What diagnostic etiologies would you consider based on the imaging features?

2. What is the next step in the workup? 
Table Differential Diagnosis of Bilateral Middle Cerebellar Peduncle (MCP) Signs in Our Patient

\begin{tabular}{ll}
\hline Differential diagnosis & Key differential points \\
\hline Hypoglycemia coma & No historical clue \\
\hline Osmotic demyelination syndrome & No historical clue \\
\hline Wallerian degeneration & No pontine lesion \\
\hline Toxic leukoencephalopathy & No historical clue \\
\hline Hepatic encephalopathy & No historical clue; normal liver function, ammonia level, and ultrasound findings \\
\hline Wilson disease & Unremarkable serum ceruloplasmin finding \\
\hline Hereditary motor and sensory neuropathy, type VI & Normal EMG \\
\hline Ischemic stroke & Chronic onset and progressive development not consistent; MRA and DWI may be needed \\
\hline Multiple system atrophy & No evidence supporting autonomic dysfunction
\end{tabular}

Abbreviations: DWI = diffusion-weighted imaging; MRA = magnetic resonance angiography.

\section{Section 3}

According to the clinical presentation of tremor and radiologic features (bilateral MCP signs), fragile X-associated tremor/ ataxia syndrome (FXTAS) was initially suspected. However, the patient was female and had no family history, which is not characteristic for FXTAS. Additionally, genetic testing for FMR1 was negative. Other potential entities with bilateral MCP signs were excluded; the key points are summarized in the table.

To better characterize these abnormalities, magnetic resonance angiography (MRA), diffusion-weighted imaging (DWI), apparent diffusion coefficient (ADC) mapping, and contrastenhanced T1-weighted imaging (T1WI) were performed. Brain MRA and contrast-enhanced TIWI findings were unremarkable. DWI showed hyperintensity and ADC mapping showed isointensity in the bilateral MCPs. In addition, DWI and ADC mapping showed hyperintensity in the corticomedullary junction and corpus callosum (Figure, B).

\section{Questions for Consideration:}

1. What is your diagnosis?

2. How can the diagnosis be confirmed?

\section{GO TO SECTION 4}




\section{Section 4}

Although hyperintensity in the corticomedullary junction on DWI is occasionally observed in patients with FXTAS, oculopharyngeal myopathy with leukoencephalopathy, and cystathionine $\beta$-synthase deficiency, ${ }^{1,2}$ it is also an important clue in the diagnosis of adult-onset neuronal intranuclear inclusion disease (NIID). ${ }^{3}$ To confirm this diagnosis, skin biopsy was performed; electron microscopic analysis revealed intranuclear inclusions in the sweat gland cells (Figure, C). Ultimately, adult-onset NIID was diagnosed. Further genetic testing for NOTCH2NLC was negative. As NIID has no known cure, the patient was started on symptomatic treatment (levodopa/benserazide, $125 \mathrm{mg} 3$ times a day), but she did not respond. Thus, the treatment was changed to propranolol ( $10 \mathrm{mg}$ orally 3 times a day), and the patient's tremor symptoms improved.

\section{Discussion}

NIID is a slowly progressing neurodegenerative disease characterized by localized neuronal loss and eosinophilic hyaline intranuclear inclusions in the nervous system, skin, and visceral organs. ${ }^{4}$ According to the age at onset, NIID is classified as the infantile, juvenile, or adult form. The clinical presentations of the adult form of NIID are highly variable, and may include dementia, parkinsonism, peripheral neuropathy, encephalopathy, or autonomic impairment. ${ }^{4}$ In patients presenting with isolated or predominant tremor, the suspicion and subsequent diagnosis of NIID may be delayed.

The clinical heterogeneity of NIID increases the difficulty of antemortem diagnosis. In certain Asian populations (e.g., Japanese and Chinese), NIID is much more common than FXTAS. Neuroimaging and skin biopsy are helpful for its antemortem diagnosis. The neuroradiologic characteristics of NIID include hyperintensity in the corticomedullary junction on DWI and hyperintensity in the paravermal area and bilateral MCP signs on FLAIR sequences. ${ }^{5}$ High-intensity signals along the corticomedullary junction on DWI have been correlated with pathologic spongiotic changes and eosinophilic hyaline inclusions in astrocytes, which damage the white matter. ${ }^{6}$ However, the main radiologic signs of NIID have also been reported for other diseases, including FXTAS, although subcortical brain hyperintensity on DWI is more specific to NIID than to FXTAS. ${ }^{1}$ Skin biopsy is essential to help distinguish NIID from other diseases. ${ }^{7}$ As the clinical manifestations, radiologic features, histopathologic findings, and even molecular basis (i.e., expanded CGG repeats) of FXTAS and NIID can overlap, genetic testing for FMR1 is important to distinguish the 2 conditions. ${ }^{1}$

Recent studies have identified NOTCH2NLC as the main genetic cause of NIID in Japanese and Chinese patients. ${ }^{8}$ However, this finding has not been proven in European patients. ${ }^{9}$ Moreover, GGC repeat expansion has been documented in multiple diseases, including Alzheimer disease, Parkinson disease, essential tremor, frontotemporal dementia, and amyotrophic lateral sclerosis. ${ }^{10}$ In our patient, NOTCH2NLC negativity indicated that the pathogenic mechanism underlying the development of NIID is complex.

No currently available treatment cures or slows the progression of NIID. Symptomatic treatments may improve patients' quality of life. In our case, the patient's tremors responded well to propranolol treatment. Most prognoses are poor. However, early diagnosis could avoid redundant examination.

NIID should be included in the differential diagnosis in patients presenting with tremor. This case is an example of NIID characterized mainly by tremor with typical neuroradiologic findings, which led to skin biopsy and genetic testing for final diagnosis. It highlights the complexity of combined clinical examination, neuroimaging, skin biopsy, and genetic testing for the diagnosis of NIID, an uncommon etiology of tremor.

\section{Study Funding}

No targeted funding reported.

\section{Disclosure}

The authors report no disclosures relevant to the manuscript. Go to Neurology.org/N for full disclosures.

\section{Appendix Authors}

\begin{tabular}{|c|c|c|}
\hline Name & Location & Contribution \\
\hline Jing Ye, MD & $\begin{array}{l}\text { Department of Neurology, the } \\
\text { Sixth People's Hospital of } \\
\text { Chengdu, China }\end{array}$ & $\begin{array}{l}\text { Major role in the acquisition } \\
\text { of data, drafted the } \\
\text { manuscript }\end{array}$ \\
\hline $\begin{array}{l}\text { Hua Cao, } \\
\text { MD }\end{array}$ & $\begin{array}{l}\text { West China School of Nursing/ } \\
\text { Departments of } \\
\text { Neurosurgery, West China } \\
\text { Hospital, Sichuan University, } \\
\text { Chengdu, China }\end{array}$ & $\begin{array}{l}\text { Interpreted the data, } \\
\text { revised the manuscript for } \\
\text { intellectual content }\end{array}$ \\
\hline $\begin{array}{l}\text { Lizhang } \\
\text { Chen, MD }\end{array}$ & $\begin{array}{l}\text { Department of Neurology, } \\
\text { West China Hospital, Sichuan } \\
\text { University, Chengdu, China }\end{array}$ & $\begin{array}{l}\text { Designed and } \\
\text { conceptualized study, } \\
\text { analyzed the data, drafted } \\
\text { the manuscript for } \\
\text { intellectual content }\end{array}$ \\
\hline $\begin{array}{l}\text { Song Lei, } \\
\text { MD }\end{array}$ & $\begin{array}{l}\text { Department of Pathology, } \\
\text { West China Hospital, Sichuan } \\
\text { University, Chengdu, China }\end{array}$ & $\begin{array}{l}\text { Major role in the acquisition } \\
\text { of skin biopsy }\end{array}$ \\
\hline Mei Liu, MD & $\begin{array}{l}\text { Department of Neurology, the } \\
\text { Sixth People's Hospital of } \\
\text { Chengdu, China }\end{array}$ & $\begin{array}{l}\text { Major role in the acquisition } \\
\text { of data }\end{array}$ \\
\hline $\begin{array}{l}\text { Xiuying } \\
\text { Long, MD }\end{array}$ & $\begin{array}{l}\text { Department of Neurology, the } \\
\text { Sixth People's Hospital of } \\
\text { Chengdu, China }\end{array}$ & $\begin{array}{l}\text { Major role in the acquisition } \\
\text { of data }\end{array}$ \\
\hline $\begin{array}{l}\text { Guangzong } \\
\text { Li, MD }\end{array}$ & $\begin{array}{l}\text { Department of Neurology, the } \\
\text { Sixth People's Hospital of } \\
\text { Chengdu, China }\end{array}$ & $\begin{array}{l}\text { Interpreted the data, } \\
\text { revised the manuscript for } \\
\text { intellectual content }\end{array}$ \\
\hline $\begin{array}{l}\text { Hongbo } \\
\text { Zheng, MD }\end{array}$ & $\begin{array}{l}\text { Department of Neurology, } \\
\text { West China Hospital, Sichuan } \\
\text { University, Chengdu, China }\end{array}$ & $\begin{array}{l}\text { Interpreted the data, } \\
\text { revised the manuscript for } \\
\text { intellectual content }\end{array}$ \\
\hline
\end{tabular}




\section{References}

1. Ishiura H, Shibata S, Yoshimura J, et al. Noncoding CGG repeat expansions in neuronal intranuclear inclusion disease, oculopharyngodistal myopathy and an overlapping disease. Nat Genet. 2019;51(8):1222-1232.

2. Ruhoy IS, Merritt JL, Amlie-Lefond C. Cystathionine beta-synthase deficiency heralded by cerebral sinus venous thrombosis and stroke. Pediatr Neurol. 2014;50(1):108-111.

3. Chen L, Chen A, Lei S, He L, Zhou M. Teaching NeuroImages: the zigzag edging sign of adult-onset neuronal intranuclear inclusion disease. Neurology. 2019;92(19):e2295-e2296.

4. Sone J, Mori K, Inagaki T, et al. Clinicopathological features of adult-onset neuronal intranuclear inclusion disease. Brain. 2016;139(pt 12):3170-3186.

5. Sugiyama A, Sato N, Kimura Y, et al. MR imaging features of the cerebellum in adultonset neuronal intranuclear inclusion disease: 8 cases. Am J Neuroradiol. 2017;38(11): 2100-2104.
6. Suthiphosuwan S, Sasikumar S, Munoz DG, Chan DK, Montanera WJ, Bharatha A MRI diagnosis of neuronal intranuclear inclusion disease leukoencephalopathy. Neurol Clin Pract. 2019;9(6):497-499.

7. Sone J, Tanaka F, Koike H, et al. Skin biopsy is useful for the antemortem diagnosis of neuronal intranuclear inclusion disease. Neurology. 2011;76(16): 1372-1376.

8. Tian Y, Wang J-L, Huang W, et al. Expansion of human-specific GGC repeat in neuronal intranuclear inclusion disease-related disorders. Am J Hum Genet. 2019; 105(1):166-176

9. Yau WY, Sullivan R, Chen Z, et al. GGC repeat expansion in NOTCH2NLC is rare in European leukoencephalopathy. Ann Neurol. 2020;88(3):641-642.

10. Jiao B, Zhou L, Zhou Y, et al. Identification of expanded repeats in NOTCH2NLC in neurodegenerative dementias. Neurobiol Aging. 2020;89:142.e1-142.e7. 


\section{Neurology}

\section{Clinical Reasoning: A 65-Year-Old Woman With Tremor}

Jing Ye, Hua Cao, Lizhang Chen, et al.

Neurology 2021;97;e1257-e1261 Published Online before print May 26, 2021

DOI 10.1212/WNL.0000000000012262

This information is current as of May 26, 2021

\section{Updated Information \& Services}

References

Subspecialty Collections

Permissions \& Licensing

Reprints including high resolution figures, can be found at: http://n.neurology.org/content/97/12/e1257.full

This article cites 10 articles, 4 of which you can access for free at: http://n.neurology.org/content/97/12/e1257.full\#ref-list-1

This article, along with others on similar topics, appears in the following collection(s):

CME

http://n.neurology.org/cgi/collection/cme

DWI

http://n.neurology.org/cgi/collection/dwi

Tremor

http://n.neurology.org/cgi/collection/tremor

Information about reproducing this article in parts (figures,tables) or in its entirety can be found online at:

http://www.neurology.org/about/about_the_journal\#permissions

Information about ordering reprints can be found online:

http://n.neurology.org/subscribers/advertise

Neurology ${ }^{\circledR}$ is the official journal of the American Academy of Neurology. Published continuously since 1951, it is now a weekly with 48 issues per year. Copyright @ 2021 American Academy of Neurology. All rights reserved. Print ISSN: 0028-3878. Online ISSN: 1526-632X.

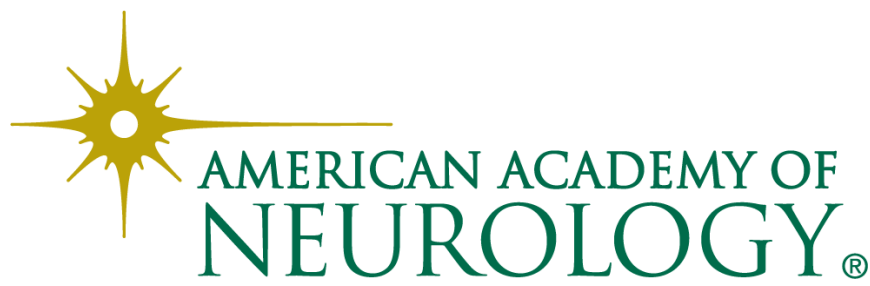

